Jurnal KIBASP (Kajian Bahasa, Sastra dan Pengajaran)

Volume 2, Nomor 1, Desember 2018

e-ISSN : 2597-5218

p-ISSN : 2597-520X

DOI: https://doi.org/10.31539/kibasp.v2i1.409

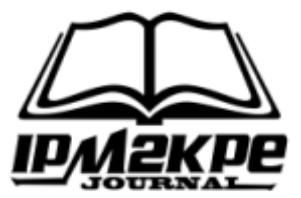

\title{
UNSUR PEMBANGUN NASKAH DRAMA GENTAYU ULAK DALAM KARYA RUSMANA DEWI
}

\author{
Agung Nugroho \\ Program Studi Bahasa dan Sastra Indonesia STKIP-PGRI Lubuklinggau \\ agung.nugroho12354@gmail.com
}

Submit, 05-11-2018 Accepted, 27-12-2018 Publish, 29-12-2018

\begin{abstract}
ABSTRAK
Penelitian ini bertujuan untuk menganalisis struktur naskah drama cerita rakyat Musi Rawas melalui pendekatan struktural. Pendekatan yang digunakan dalam penelitian ini adalah pendekatan deskriptif kualitatif dalam sudut pandang penelitian kepustakaan. Teknik pengumpulan data terdiri dari teknik baca, teknik infentarisasi, dan teknik pencatatan. Seluruh data yang diperoleh dari hasil pembacaan dan pengodean dipilah berdasarkan objek penelitian, dan data yang telah dipilah-pilah dideskripsikan sebagai mana adanya dan disusun dalam bentuk laporan. Hasil penelitian, konflik yang terjadi dalam naskah, yaitu ketika Gentayu tahu kalau ibu kandungnya masih hidup dan terus berusaha bertemu, sehingga menyebakan Remas Samar ayah Gentayu menjadi marah. Hal ini yang menjadi sentral permasalahan atau konflik dalam naskah drama cerita rakyat Musi Rawas "Gentayu Ulak Dalam". Adapun alur yang terdapat dalam naskah ini, yaitu alur maju. Latar dalam naskah drama ini yaitu di Kampung, Hutan, Bukit Batu dan Sungai. Simpulan, berdasarkan analisis yang penulis lakukan pada naskah drama merupakan jenis drama tragedi, karena klimaks dari cerita mengambarkan kesedihan dan kematian
\end{abstract}

Kata Kunci: Analisis, Naskah Drama, Pendekatan Struktural.

\begin{abstract}
The research objective was to analyze the structure of drama manuscript of Musi Rawas folklore. The approach used was qualitative descriptive approach with library research method. The data were collected through reading technique, inventory technique and noting technique. The data were obtained from reading and coding were classified based on the object, described, organized into the report. The results presented: the conflict was when Gentayu recognized her mother was still alive and she kept meeting her, so that Remas Samar, whose father, was angry. It becomes the main problem in drama manuscript in Musi Rawas folklore "Gentayu Ulak Dalam". The plot in the drama was straightforward. The settings were in the village, forest, Baru Hill and river. In conclusion, according to the analysis, the drama included as tragedy because the climax of the story described the sadness and death.
\end{abstract}

Keywords: Analysis, Drama Manuscript, Structural Approach 


\section{PENDAHULUAN}

Sastra adalah karya seni hasil pemikiran dan imajinasi dari seseorang, oleh sebab itu sastra dapat melatih kecerdasan seseorang.Dalam karya sastra terdapat beberapa bentuk, diataranya prosa dan puisi.Prosa adalah bentuk karya sastra yang tidak terikat oleh aturan seperti puisi, dan bahasanya banyak mangandung bahasa sehari-hari (Rozak. 2007). Beberapa jenis prosa diataranya, novel, cerpen, cerita rakyat dan drama.Puisi adalah seni tertulis di mana bahasa digunakan untuk kualitas estetiknya untuk tambahan, atau selain arti semantiknya (Wibowo, 2013). Jadi bentuk karya sastra Nusantara ini dapat membantu seseorang untuk melatih kecerdasan apa bila sastra tersebut dapat dipahami secara menyeluruh.

Prosa merupakan salah satu bentuk sastra yang cukup mudah dipahami oleh setiap pembaca, hal ini karena sastra prosa tidak banyak menggunakan kata kias (Konotasi). Di dalam prosa banyak mengandung makna dan pesan yang ingin disampaikan oleh pengarang ke pada pembaca umum.Dalam beberapa jenis prosa ada yang dipentaskan dan adapulan yang hanya cukup dibaca atau didengar.Bentuk prosa yang dipentaskan misalnya drama, dan yang dibaca contohnya, novel, cerpen, hikayat dan lainya. Sedangkan beberapa contoh prosa yang disimak antara lain, dongeng, cerita rakyat dan lainya.

Berdasarkan beberapa bentuk prosa tersebut, drama merupakan bentuk prosa yang sulit dipahami secara cepat, hal ini karena pesan yang disampaikan dalam drama bisa berbentuk tulis atau lisan (tersirat). Oleh sebab itu sebuah drama memerlukan pemahaman pada tingkatan yang lebih tinggi. Drama tidak cukup dipahami melalui bentuk pentasnya saja, akan tetapi juga harus dikaji dalam bentuk naskahnya, agar makna dan pesan drama dapat tersampaikan dengan baik.

Drama adalah satu bentuk karya sastra yang memiliki bagian untuk diperankan oleh aktor (Wibowo. 2013).Menurut pengertiannya drama merupakan bentuk karya sastra prosa yang dipentaskan dengan berpedoman pada naskah drama (Skenario), oleh sebab itu untuk memahami drama secara baik harus benar-benar memahami naskah dramanya. Dalam memahami dan mengapresiasi sebuah naskah drama penulis dapat menggunakan beberapa pendekatan sesuai dengan apa yang ingin diapresiasi. Apresiasi adalah penghargaan, penilaian dan pengertian terhadap karya sastra baik dalam bentuk puisi maupun prosa 
(Muslich. 2009).Jadi dapat disimpulkan apresiasi naskah drama adalah salah satu kegiatan penilaian terhadap naskah drama, dalam hal ini naskah drama cerita rakyat Musi Rawas.

Penulis akan menemukan unsur intrinsik naskah drama cerita rakyat Musi Rawas, oleh sebab itu penulis memilih pendekatan objektif/struktural. Menurut Endraswara (2011) Pendekatan objektif/struktural adalah pendekatan pendekatan yang menitik beratkan pada unsur struktural/ intrinsik sastra itu sendiri. Struktural pada dasarnya merupakan cara berfikir tetang dunia yang berhubungan dengan tanggapan dan deskripsi struktur-truktur sastra. Prinsipnya, keutuhan makna bergantung pada hubungan keseluruhan struktur sastra. Hal ini karena struktur satu dengan lainya saling berhubungan untuk menunjang suatu makna sastra.

Penelitian yang penulis lakukan relevan dengan penelitian Herawati, dkk (2018), dengan judul “Analisis Struktur Naskah Drama Raja Galau”. Hasil penelitian yang dilakukan Herawati, dkk menunjukan tema raja yang bijaksana memiliki 10 tokoh dalam naskah drama, selain itu naskah drama beralur lurus, dan secara garis besar mengandung amanat jangan mengambil hak orang lain untuk kepentingan pribadi. Dari hasil tersebut antara Herawati, dkk dan penulis memiliki kesamaan pendekatan kajian sastranya yaitu pendekatan struktural. Objek kajian memiliki kesamaan yaitu berkaitan dengan naskah drama sedangkan perbedaan terletak pada judul naskah drama yang digunakan.

Naskah drama yang penulis gunakan adalah naskah drama cerita rakyat Musi Rawas dalam kumpulan cerita rakyat Musi Rawas yang disusun oleh Dr. Rusmana Dewi, M.Pd. Diharapkan dengan analisis naskah drama cerita rakyat Musi Rawas dapat membantu mahasiswa dan pembaca umum untuk lebih memahami makna dan pesan yang ada dalam naskah drama tersebut. Naskah drama cerita rakyat Musi Rawas menggambarkan kehidupan masyarakat Musi Rawas pada masa lampau yang tidak semua pembaca khususnya mahasiswa STKIP-PGRI Lubuklinggau memahaminya, sehingga membuat pembaca tidak menyukai bentuk karya sastra ini. 


\section{METODE PENELITIAN}

Pendekatan yang digunakan dalam penelitian ini adalah pendekatan deskriptif kualitatif dalam sudut pandang penelitian kepustakaan. Dikatakan deskriptif kualitatif karena penelitian ini, penulis mendeskripsikan data yang dianalisis berupa unsur-unsur intrinsik naskah drama Cerita Rakyat Musi Rawas “Gentayu Ulak Dalam”. Sesuai dengan kenyataan yang ditemukan dalam penelitian. Dikatakan deskriptif kualitatif karena dalam menjelaskan konsep-konsep yang berkaitan antara yang satu dengan yang lain, penulis menggunakan kata-kata atau kalimat bukan angka-angka statistik dengan mengacu pada struktur yang benar serta menggunakan pemahaman yang mendalam. Jenis penelitian kepustakaan ini dilakukan dengan menganalisis naskah drama Cerita Rakyat Musi Rawas “Gentayu Ulak Dalam”.

Data dalam penelitian ini adalah kutipan-kutipan cerita yang mencerminkan unsurunsur intrinsik naskah drama cerita rakyat Musi Rawas “Gentayu Ulak Dalam”.Sumber data dalam penelitian ini adalah kumpulan naskah drama cerita rakyat Musi Rawas, dengan judul naskah drama "Gentayu Ulak Dalam”. Pengumpulan data dalam penelitian ini di lakukan dengan tiga teknik yaitu:

1. Teknik Baca. Membaca dengan seksama dengan berulang-ulang.Kegiatan membaca dalam hal ini, penulis membaca secara seksama naskah drama cerita rakyat Musi Rawas (Gentayu Ulak Dalam).

2. Teknik Infentarisasi. Mencari dan mengumpulkan sejumlah data dari naskah drama cerita rakyat Musi Rawas “Gentayu Ulak Dalam”. Data yang dicari adalah unsur-unsur intrinsik naskah drama cerita rakyat Musi Rawas “Gentayu Ulak Dalam”.

3. Teknik Pencatatan. Setelah baca simak, inventarisasi, hasil yang diperoleh dicatat dan dipilah-pilah satu persatu, sesuai dengan unsur-unsur yang dicari. Disusun secara sitematis oleh penulis agar mudah untuk dipahami dan diolah.

Adapun langkah-langkah yang ditempuh dalam menganalisis data adalah melakukan pembacaan secara berulang-ulang terhadap naskah drama cerita rakyat Musi Rawas "Gentayu Ulak Dalam", menandai setiap data yang mengandung unsur-unsur intrinsik (pemodean data), seluruh data yang diperoleh dari hasil pembacaan dan pengodean 
dipilah berdasrkan objek penelitian, dan data yang telah dipilah-pilah dideskripsikan sebagai mana adanya dan disusun dalam bentuk laporan.

\section{HASIL PENELITIAN}

Tema mayor dari naskah drama ini yakni dari kisah Gentayu Ulak Dalam ini adalah kisah seorang ayah dari kepala suatu suku yang bernama Ulak Dalam yang merahasiakan keberadaan ibu kandung dari anaknya, yang mana ibunya berasal dari suku lain yaitu dari daerah bukit batu yang ditanamkan nenek moyang tidak boleh menikah dari suku dari bukit batu tersebut, dan apabila anak tersebut mengetahui rahasia itu maka nenek moyangnya marah besar. Tema minor dari naskah drama ini, diantaranya sebagai berikut. Kepercayaan tentang ritual-ritual dan mantra-mantra untuk menghilangkan roh-roh jahat. Seorang anak yang terlahir dari seseorang suku lain yang diharamkan nenek moyang dari suku ayahnya.

Berdasarkan tema naskah drama cerita rakyat Musi Rawas "Gentayu Ulak Dalam" di atas tergambar tema utama didukung oleh tema penunjangnya sehingga tema yang terdapat dalam naskah tersebut lebih jelas.Sesuai dengan teori tema adalah pokok pikiran utama dari sebuah teks atau wacana.Dimana sebuah tema yang baik apabila tema utama didukung oleh tema-tema yang lebih khusus. Dalam naskah drama cerita rakyat Musi Rawas "Gentayu ulak Dalam” tergambar jelas jika temanya adalah mengenai masyarakat Musi Rawas pada masa lampau dimana belum mengenal agama dengan pola pikir yang kolot, dengan kepercayaan Animisme yang membuat kehidupan mereka dibelenggu oleh aturan-aturan adat yang tidak masuk diakal sehat.

Kehidupan dimana keluarga belum menjadi prioritas utama dibandingkan dengan status sosial, walaupun dalam kenyataanya hal ini masih terjadi pada masa sekarang ini. Jadi dapat diambil kesimpulan jika tema cerita "Gentayu Ulak Dalam” ini adalah realita gambaran kehidupan masyarakat Musi Rawas pada masa lampau yang masih memegang adat istiadat dengan kepercayaan yang mereka yakini walau hal itu salah, sehingga membawa dampak yang besar bagi kehidupan mereka. 
Tokoh adalah individu rekaan yang mengalami peristiwa dan perlakuan dalam berbagai peristiwa cerita (Sujiman dalam Maslikatin, 2007).Peran tokoh dalam cerita ini dibedakan menjadi dua, yakni tokoh utama dan tokoh bawahan.Tokoh utama dalam cerita ini adalah Gentayu, di damana dalam setiap dialog selalu membeicarakan gentayu. Jadi dapat disimpulkan bahwa tokoh utama dalam drama Gentayu Ulak Dalam adalah gentayu.Watak yang dimiliki oleh gentayu yaitu: keras kepala, pemberani, dan peduli.

Tokoh bawahan satu yang mendukung tokoh utama yaitu Remas Samar, terlihat banyak dilaog yang terjadi antara Gentayu dan Remas Samar.Remas Samar adalah ayah dari tokoh utama, dimana peran yang diberikan memberikan kesan selalu menentang dari tokoh utama.Tokoh bawahan satu juga adalah tokoh yang memberikan dampak besar dari klimaks naskah drama ini.Tokoh bawahan 1 memiliki watak pemarah, kejam, pembohong. Tokoh bawahan dua dalam naskah drama ini adalah Sunti yaitu ibu dari gentayu yang muncul pada akhir cerita sebagai penengah bertugas mendamaikan atau menjadi perantara protagonis dan antagonis Sunti hanya memiliki adegan yang tidak banyak, hal ini karena Sunti hanya beradegan pada klimaks saja, walaupun dalam dialog antar tokoh sering disebutkan oleh para tokoh. Fungsi tokoh Sunti ini juga sangat fital hal ini karena Sunti memberikan kesan klimaks yang dramatis.

Watak tokoh ini, pembela, rela berkorban dan penyayang.Tokoh bawahan tiga yang terlihat dalam naskah drama ini adalah Kemunting yang muncul setiap berdialog dengan Remas Samar. Kemunting juga sebagai tokoh pelengkap hanya ada beberapa dialog yang muncul dalam naskah drama ini dan kemunting mempunyai beberapa watak yang diperankannya yaitu, pemberi sabar, pencemas. Tokoh bawahan empat ini adalah beberapa tokoh yang menjadi pelengkap dalam kisah ini yaitu Mudun dan Sungkai.Mudun dan Sungkai sebagai orang bawahan Remas Samar.Beberapa watak yang dimillki oleh Mudun dan Sungkai yaitu, penurut.Seorang ke satu memillki watak yang suka mendugaduga.Seorang ke dua memilki watak yang selalu menyakinkan kemampuan Gentayu. Terlihat saat seorang ke satu menduga-duga dan menepis dugaan tersebut.Seorang ke tiga memilki watak yang pengadu, dimana seorang ke tiga mengetahui keberadaan Gentayu, dan mengadukannya kepada Remas Samar. 
Alur adalah sesuatu yang penting terdapat di dalam sebuah naskah drama supaya pembaca dapat mengetahui maksud dan arah dalam sebuah cerita. Adapun bagian alur dalam naskah drama ini yaitu: Situation dalam teks drama Gentayu Ulak Dalam bagian suasana dalam cerita sejak mulai masuk cerita.Pengambaran suasana kampung sederhana, dengan masyarakat yang sedikit dengan kehidupan yang alami.Dalam Situation ini juga tergambar sudah mulainya bertemu antara tokoh utama dan tokoh lainya.Generating circumstances, dalam hal ini untuk alur cerita sudah mulai agak nampak dengan mengenalkan beberapa konfliknya kepada para tokohnya, yang mana telah nampak setelah ritual berlangsung.

Pada hal ini terlihat konflik ringan yang terjadi antara tokoh utama dengan tokoh bawahan, dimana perselisihan mulai nampak, dengan suasana yang cukup menegangkan.Rising action, ketika gentayu pada hari mulai petang tetapi balum pulang juga.Climaks, hal ini dapat diketahui dari babak III, ketika Remas Samar ingin membunuh Gentayu anak kandungnya sendiri dan munculnya Sunti di tengah perselisihan itu.Denouement, dalam babak ini konflik yang memuncak semakain menjadi jadi dan akhir cerita dapat di ketahui dengan kedatangan ibu Gentayu nyaitu Sunti yang membela Gentayu yang akhirnya mati. Alur yang ada dalam naskah drama ini berjalan lurus dari konflik terkecil kamudian besar dan akhir dari cerita yaitu kematian dari ibu Gentayu sehingga dapat ditarik kesimpulan bahwa alur dari naskah drama ini adalah alur lurus.

Latar (Setting) adalah tempat terjadinya peristiwa dalam cerita atau lingkungan yang mengelilingi pelaku.Latar juga menunjukkan local colour atau warna lokal. Di dalam naskah Gentayu Ulak Dalam juga di jelaskan beberapa latar yang ada yaitu:Latar Tempat, ada beberapa latar tempat yang tergambar dalam naskah drama ini yaitu: perkampungan di sebuah hutan, daerah sungai, daerah perbukitan, Latar waktu yang digunakan dalam naskah drama Gentayu Ulak Dalam adalah waktu petang. Latar suasana yang tergambar dalam naskah drama Gentayu Ulak Dalam adalah suasana yang menegangkan dilihat dari percakapan pertama hingga akhir selalu di tandai dengan perseturan antara Gentayu dan ayahnya yaitu Remas Samar, dan di akhir cerita terjadi perseteruan antara Sunti ibu kandung Gentayu dan Remas Samar. 
Konflik yang terjadi dalam naskah drama Gentayu Ulak Dalam adalah konflik fisik atau eksternal yaitu konflik manusia dengan manusia.Konflik ini terjadi antara Remas Samar dan Gentayu ini terlihat di setiap dilaog selalu muncul perseteruan antara Remas Samar dan Gentayu. Selain itu konflik lain yang terjadi manusi dengan manusia yaitu konflik antara remas samar dan sunti.

Amanat yang dapat diambil dari naskah drama Gentayu Ulak Dalam adalah Sebagai mahluk hidup yang bermasyarakat, tentu tidak bisa terlepas dari makhluk hidup yang lain. Karena kita membutuhkan satu sama lain. Kita harus bersikap sama antara makhluk yang satu dengan yang lain tanpa membedakan status sosial. Apabila seseorang menyimpan rahasia, suatu saat pasti akan terungkap hal yang sebenarannya, dan apabila seseorang dengan penuh kesabaran dan keikhlasan dalam melakukan sesuatu maka orang tersebut juga akan mendapatkan balasan yang baik.

Sedalam-dalamnya kita mengubur bangkai akan tercium juga bau-nya. Begitu juga dengan Remas Samar sepandai-pandainya Remas samar menyimpan rahasia tentang latar belakang Gentayu maka tetap akan ketahuan oleh Gentayu, dan juga drama ini mengajarkan kita tidak untuk berbohong, karena akan menyebabkan kerugian atau kehancuran bagi diri kita sendiri dan disekitarnya.

Amanat yang tidak kalah pentingnya adalah tentang Pengorbanan Seorang ibu yang bernama Sunti yang merelakan dirinya untuk anaknya yang bernama Gentayu yang ingin dibunuh oleh ayah kandungnya sendiri yang bernama Remas Samar dengan senjata tombak yang di milikinya.

Sudut pandang penokohan dalam drama Gentayu Ulak Dalam ini sudah jelas, karena dapat dilihat dari penamaan para tokohnya.Dalam pengisahan cerita yang mempergunakan sudut pandang orang pertama, 'aku', narator adalah seseorang yang ikut terlibat dalam cerita.Ia adalah si 'aku' tokoh yang berkisah, mengisahkan kesadaran dirinya sendiri, mengisahkan peristiwa atau tindakan, yang diketahui, dilihat, didengar, dialami dan dirasakan, serta sikapnya terhadap orang (tokoh) lain kepada pembaca. Jadi, pembaca hanya dapat melihat dan merasakan secara terbatas seperti yang dilihat dan dirasakan tokoh si 'aku' tersebut.Gentayu menggunakan sudut pandang orang pertama dalam drama Gentayu Ulak Dalam. 
Dalam cerita yang mempergunakan sudut pandang orang ketiga, 'dia', narator adalah seorang yang berada di luar cerita, yang menampilkan tokoh-tokoh cerita dengan menyebut nama, atau kata gantinya: ia, dia, mereka. Nama-nama tokoh cerita, khususnya yang utama, kerap atau terus menerus disebut, dan sebagai variasi dipergunakan kata ganti.Sunti menggunakan sudut pandang orang ketiga dalam drama Gentayu Ulak Dalam. Gaya Bahasa yang terdapat dalam Drama Gentayu Ulak Dalam adalah Gaya bahasa perumpamaan, Gaya bahasa metafora, Antisipasi, Gaya bahasa Paradoks dan Klimak.

\section{PEMBAHASAN}

Berdasarkan penjelasan di atas tergambar begitu jelas isi dari naskah drama cerita rakyat Musi Rawas “Gentayu Ulak Dalam” bahwa kehidupan masyarakat Musi Rawas pada masa itu belum mengenal agama akan tetapi memiliki kepercayaan terhadap roh nenek moyang Animisme dimana dipegang teguh oleh masyarakatnya. Dampak dari kepercayaan ini memberikan sumbangan konflik yang luar biasa dalam cerita "Gentayu Ulak Dalam" ini. Dimana tokoh mengalamai gesekan karena ingin memegang kepercayaan agar terhindar dari bencana dan bahaya, akan tetapi justru memberikan hal buruk yang tidak pernah disangka dari masing-masing tokoh. Berdasarkan tema, alur, seting, tokoh, konflik dan unsur lainya naskah drama ini sudah memenuhi kriteria naskah drama yang baik hal ini dapat dilihat dari terpenuhinya struktur yang membentuk karya sastra ini.Selain itu nakah drama "Gentayu Ulak Dalam" ini penuh dengan ajaran moral dan sosial yang perlu diketahui oleh pembaca.Cerita yang penuh konflik dan dramatis.Bagi peneliti lanjutan untuk melanjutkan penelitian naskah drama ini dari ekstrinsiknya agar naskah drama ini dapat tergali secara keseluruhan.

\section{SIMPULAN}

Berdasarkan analisis yang penulis lakukan pada naskah drama cerita rakyat Musi Rawas “Gentayu Ulak Dalam” merupakan jenis drama tragedi, karena klimaks dari cerita mengambarkan kesedihan dan kematian. Adapun tokoh yang terdapat dalam naskah drama tersebut:Tokoh utama dalam cerita ini adalah Gentayu dengan watak keras kepala, pemberani, dan peduli.Tokoh bawahan satu Remas Samar, watak pemarah, kejam, 
pembohong. Tokoh bawahan duaSunti watak tokoh ini, pembela, rela berkorban dan penyayang.Tokoh bawahan tiga Kemunting watak pemberi sabar, pencemas.Tokoh bawahan empat ini Mudun dan Sungkai watak penurut.Seorang ke satu memiliki watak yang suka menduga-duga.Seorang ke dua memilki watak yang selalu menyakinkan kemampuan Gentayu. Seorang ke tiga memilki watak yang pengadu.

Adapun konflik yang terjadi dalam naskah tersebut, yaitu ketika Gentayu tahu kalau ibu kandungnya masih hidup dan terus berusaha bertemu, sehingga menyebakan Remas Samar ayah Gentayu menjadi marah.Hal ini yang menjadi sentral permasalahan atau konflik dalam naskah drama cerita rakyat Musi Rawas “Gentayu Ulak Dalam”.Adapun alur

yang terdapat dalam naskah ini, yaitu alur maju.Latar dalam naskah drama ini yaitu di Kampung, Hutan, Bukit Batu dan Sungai.

\section{DAFTAR PUSTAKA}

Endraswara, Suwardi. (2011). Metode Pembelajaran Drama. Yogyakarta: CAPS

Herawati, Lilik. (2018). Analisis Struktural Naskah Drama Raja Galau. Cirebon: Jurnal Indonesian Language Edukation and Literature. ISSN. 2502-2261. 3(2):171-180.

Malikastin, Titik. (2007). Pengantar Ilmu Sastra. Jember: FSU

Muslich, Masnur. (2009). Latihan Apresiasi Sastra. Jakarta: Triana Media.

Rozak, Abdul. (2007). Kamus Sastra. Jakarta: Balai Bahasa

Wibowo, Hakim. (2013). Sastra Indonesia. Jakarta: PADI 